Comments on: "The effect of substituent groups on the reductive degradation of azo dyes by zerovalent iron” By Hou M. et al. J. Hazard. Mater. 145 (2007) 305.

\author{
C. Noubactep \\ Centre of Geosciences, University of Göttingen, Goldschmidtstraße 3, D - 37077 Göttingen, Germany. \\ (*) corresponding author: cnoubac@gwdg.de; Tel. +49 55139 3191, FAX: +49 551399379
}

\begin{abstract}
This letter discusses possible improvements in experimental conditions to enable a purposeful discussion on the effect of substituent groups on the reductive degradation of azo dyes by elemental iron $\left(\mathrm{Fe}^{0}\right)$ in a recent article by $\mathrm{M}$. Hou and his co-workers. Also recalled is the $\mathrm{pH}$ dependence of the iron corrosion mechanism which is usually overlooked in the iron technology literature.
\end{abstract}

Keywords: Adsorption; Azo dyes; iron corrosion; Béchamp Reduction.

In a recent article entitled "The effect of substituent groups on the reductive degradation of azo dyes by zerovalent iron" M. Hou and his coworkers [1] discussed the effects of different substituent groups on the degradation of azo dyes by $\mathrm{Fe}^{0}$. For this purpose: (i) Orange I (350.33 $\left.\mathrm{g} / \mathrm{mol} ; \mathrm{pK}_{\mathrm{a}}=8.2\right)$ and Methyl Orange $\left(327.34 \mathrm{~g} / \mathrm{mol}\right.$ pK $\left.\mathrm{pK}_{\mathrm{a}}=3.7\right)$ were selected as the model azo dyes with the different substituent gro ups, and Orange II $\left(350.33 \mathrm{~g} / \mathrm{mol} ; \mathrm{pK}_{\mathrm{a}}=11.2\right)$ was studied as the isomer of Orange I; (ii) the effects of the initial concentration of azo dyes, the initial $\mathrm{pH}$ value and the $\mathrm{Fe}^{0}$ dosage on the degradation kinetics were investigated. 
The study of Hou et al. [1] is very informative to researchers interested in the field of iron technology. However, the article contains areas where improvements could be made that will be discussed below.

\section{Historical Considerations}

The initial stage of the reductive degradation of azo dyes by $\mathrm{Fe}^{0}$ may be regarded as equivalent to the Béchamp reduction [2]. The Béchamp reduction is an industrially well-established method for the synthesis of aniline e.g., from nitrobenzene [3-5]. The reduction is known to take place in the presence of $\mathrm{Fe}^{0}$ and dilute acid [4] and the yield of the reaction is commonly lesser than $92 \%$ of the theoretical amount [3,5]. The main reason for these low yields is the interaction of reaction products (anilines) with iron corrosion products (iron oxides and hydroxides). In the iron technology literature, Cao et al. [6] were among the first research groups to investigate the reactions of azo dyes with $\mathrm{Fe}^{0}$ materials. Their investigations were performed in analogy to the works on the reductive degradation of organic compounds [7-10]. Therefore, the 150 years old work of Béchamp was not considered. The treatment of azo dye wastewaters by $\mathrm{Fe}^{0}$ materials aims at producing aromatic amines that are easily degraded by microorganisms [6]. Waste problems should be considered as iron oxides and hydroxides are generated in the treatment process which could act as adsorbents for azo dyes and their degradation products [11]. Hou et al. [1] should have considered this in designing their experimental procedure, in particular in selecting the initial $\mathrm{pH}$ values.

\section{Rationale for Experimental Conditions}

First of all, the used $\mathrm{Fe}^{0}$ mass loadings (BET specific surface area $7.5 \mathrm{~m}^{2} / \mathrm{g}$ ) varied from 1 to 5 $\mathrm{g} / \mathrm{L}$, corresponding to available surface areas varying from 1.5 to $7.5 \mathrm{~m}^{2}$ (in $200 \mathrm{~mL}$ solution). The cross-section of individual dye molecules is not given, the reader can not imagine whether 
the available surface area in each reaction bottle is sufficient to realized "stoichiometric" degradation (monolayer coverage of the $\mathrm{Fe}^{0}$ material). Furthermore, the mixing intensity is not specified ("vigorous stirring").

Secondly, considering the large variation in the $\mathrm{pK}_{\mathrm{a}}$ values of the individual azo dyes, their impact in the interaction with iron surface and the surface of iron oxides/hydroxides should have been addressed, for example by determining the point of zero charge (pzc) of the used $\mathrm{Fe}^{0}$ material and giving that of possible iron oxides and hydroxides relevant to the experimental conditions [12]. Figure 1 shows that from the six investigated initial $\mathrm{pH}$ values, only one $(\mathrm{pH} 2)$ was inferior to all $\mathrm{pK}_{\mathrm{a}}$ values whereas none was superior to the $\mathrm{pK}_{\mathrm{a}}$ of Orange $\mathrm{I}\left(\mathrm{pK}_{\mathrm{a}}=8.2\right)$. Ideally, at least one initial $\mathrm{pH}$ value should have been intermediate to the $\mathrm{pK}_{\mathrm{a}}$ of Orange I (8.2) and Orange II (11.4) and one should be > 11.4. It is very likely, that the interactions of the investigated azo dyes with corrosion products (iron oxides/hydroxides) are responsible for the observed differential behaviour of azo dyes. Note that, the data in figure 3, 4, and 5 of Hou et al. [1] are not obtained under the same experimental conditions. For example figure 4 depicts the degradation of azo dyes with different initial concentrations varying from 20 to $300 \mathrm{mg} / \mathrm{L}$. The initial concentrations, the $\mathrm{Fe}^{0}$ dosage, and the initial $\mathrm{pH}$ values were different for all the dyes. No justification is given for that. Moreover, the evolution of the $\mathrm{pH}$ value during the reaction is not given. It is possible that in the experiment with $\mathrm{pH} 2$ as initial $\mathrm{pH}$ value, the $\mathrm{pH}$ rose rapidly to > 4 and iron corrodes with another mechanism as discussed below.

Thirdly, from the iron corrosion literature, the tested $\mathrm{pH}$ values $(2.0,4.0,5.0,6.0,7.0$ and 7.2) can be divided into two subgroups (figure 1): $\mathrm{pH}<4$ and $\mathrm{pH} \geq 4$ [13]. At $\mathrm{pH}<4$, iron corrodes after the "hydrogen evolution mechanism" and is controlled by two key factors: the conductivity and the $\mathrm{pH}$ of the aqueous solution. At $\mathrm{pH} \geq 4$, iron corrodes after the "oxygen absorption mechanism" and is controlled by two key factors: the nature of the oxide-film (composition, 
porosity, thickness) on $\mathrm{Fe}^{0}$, and the rate of azo dye diffusion through the film [13,14]. In both cases, the mixing intensity has a great impact of the reaction rate as its accelerate species transport $[9,15]$.

\section{Conclusions}

The discussion above unequivocally show that the experimental conditions of Hou et al. [1] should have been more optimally selected. This weakness is partly due to the failure of pioneers works of the iron technology to properly consider the available literature on: (i) iron corrosion, and (ii) the use of elemental iron in the synthetic organic chemistry. Nevertheless, the authors may have pay more attention to the work of Mielczarski et al. [12] who discussed in some details the role of oxide-film on the removal of azo dyes by $\mathrm{Fe}^{0}$ in weak acidic solutions. Clearly a different choice in experimental conditions may have increased the value of the interesting work of Hou et al. [1].

\section{References}

[1] M. Hou, F. Li, X. Liu, X. Wang, H. Wan, The effect of substituent groups on the reductive degradation of azo dyes by zerovalent iron, J. Hazard. Mater. 145 (2007), 305-314.

[2] A.J. Béchamp, De l'action des protosels de fer sur la nitronaphtaline et la nitrobenzine. Nouvelle méthode de formation des bases organiques artificielles de Zinin, Ann. Chim. Phys. 42 (1854), 186-196.

[3] K. Swaminathan, P.N. Anantharaman, G.S. Subramanian, H.V.K. Udupa, Preliminary studies on the electrolytic reduction of nitrobenzene to aniline, J. Appl. Electrochem. 2 (1972), 169-173. [4] J. Werner, Amination by Reduction, Ind. Eng. Chem. 43 (1951), 1917-1919.

[5] J. Werner, Amination by Reduction, Ind. Eng. Chem. 48 (1956), 1563-1565. 
[6] J. Cao, L. Wei, Q. Huang, L. Wang, S. Han, Reducing degradation of azo dye by zero-valent iron in aqueous solution, Chemosphere 38 (1999), 565-571.

[7] A. Agrawal, P.G. Tratnyek, Reduction of nitro aromatic compounds by zero-valent iron metal. Environ. Sci. Technol. 30 (1996) 153-160.

[8] R.W. Gillham, S.F. O’Hannesin, Enhanced degradation of halogenated aliphatics by zerovalent iron. Ground Water 32 (1994), 958-967.

[9] L.J. Matheson, P.G. Tratnyek, Reductive dehalogenation of chlorinated methanes by iron metal, Environ. Sci. Technol. 28 (1994), 2045-2053.

[10] E.J. Weber Iron-mediated reductive transformations: investigation of reaction mechanism. Environ. Sci. Technol. 30 (1996), 716-719.

[11] O. Gyliene, S. Višniakova, R. Binkiene, O. Nivinskiene, A. Jagminiene, Discoloration of direct light resistant blue and acid antrachinone blue dyes using metallic iron, Chemija 17 (2006), $1-6$.

[12] J.A. Mielczarski, G.M. Atenas, E. Mielczarski, Role of iron surface oxidation layers in decomposition of azo-dye water pollutants in weak acidic solutions, Applied Catalysis B: Environ. 56 (2005), 289-303.

[13] E.R. Wilson, The Mechanism of the corrosion of iron and steel in natural waters and the calculation of specific rates of corrosion. Indust. Eng. Chem. 15 (1923), 127-133.

[14] U.R. Evans Use of Soluble Inhibitors: Fundamental principles. Ind. Eng. Chem. 37 (1945), 703-705.

[15] C. Noubactep, Contaminant reduction at the surface of elemental iron: the end of a myth (in German), TerraTech 11-12 (2006), TT11-14. 


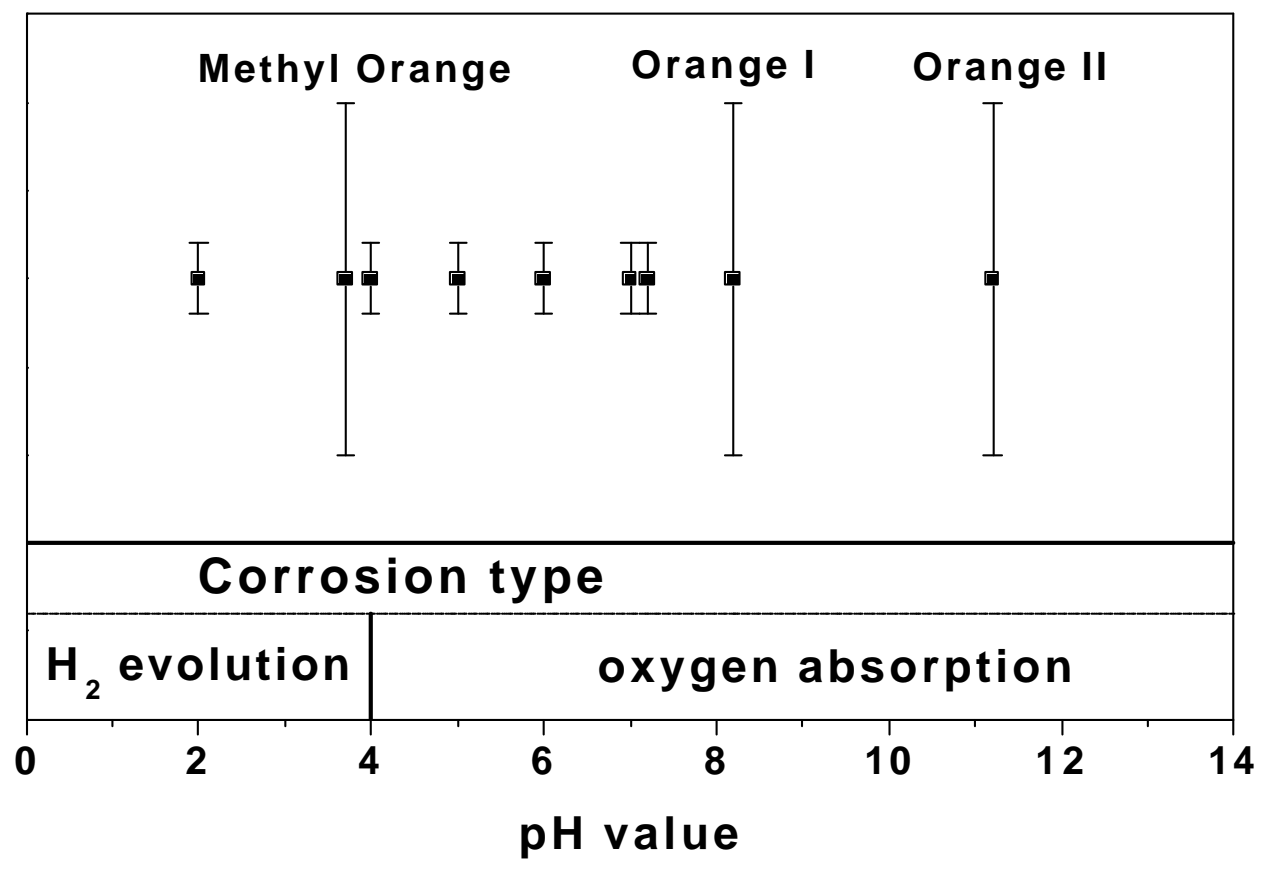

Figure 1: Comparison of the six initial $\mathrm{pH}$ values of Hou et al. [1] with the $\mathrm{pK}_{\mathrm{a}}$ values of the individual azo dyes and representation of the predominance domains for both iron corrosion types ( $\mathrm{pH}<4$ hydrogen evolution and $\mathrm{pH} \geq 4$ oxygen absorption). 